\title{
The association between fine particulate matter exposure during pregnancy and preterm birth: a meta-analysis
}

\author{
Xiaoli Sun ${ }^{1}$, Xiping Luo ${ }^{1 *}$, Chunmei Zhao', Rachel Wai Chung Ng${ }^{2}$, Chi Eung Danforn Lim²,3 Bo Zhang ${ }^{4}$
} and Tao Liu ${ }^{5,6^{*}}$

\begin{abstract}
Background: Although several previous studies have assessed the association of fine particulate matter $\left(\mathrm{PM}_{2.5}\right)$ exposure during pregnancy with preterm birth, the results have been inconsistent and remain controversial. This meta-analysis aims to quantitatively summarize the association between maternal $\mathrm{PM}_{2.5}$ exposure and preterm birth and to further explore the sources of heterogeneity in findings on this association.

Methods: We searched for all studies published before December 2014 on the association between $\mathrm{PM}_{2.5}$ exposure during pregnancy and preterm birth in the MEDLINE, PUBMED and Embase databases as well as the China Biological Medicine and Wanfang databases. A pooled OR for preterm birth in association with each $10 \mu \mathrm{g} / \mathrm{m}^{3}$ increase in $\mathrm{PM}_{2.5}$ exposure was calculated by a random-effects model (for studies with significant heterogeneity) or a fixed-effects model (for studies without significant heterogeneity).
\end{abstract}

Results: A total of 18 studies were included in this analysis. The pooled OR for PM 2.5 exposure (per $10 \mu \mathrm{g} / \mathrm{m}^{3}$ increment) during the entire pregnancy on preterm birth was $1.13(95 \% \mathrm{Cl}=1.03-1.24)$ in 13 studies with a significant heterogeneity $(\mathrm{Q}=80.51, p<0.001)$. The pooled $\mathrm{ORs}$ of $\mathrm{PM}_{2.5}$ exposure in the first, second and third trimester were $1.08(95 \% \mathrm{Cl}=0.92-1.26), 1.09(95 \% \mathrm{Cl}=0.82-1.44)$ and $1.08(95 \% \mathrm{Cl}=0.99-1.17)$, respectively. The corresponding meta-estimates of $\mathrm{PM}_{2.5}$ effects in studies assessing $\mathrm{PM}_{2.5}$ exposure at individual, semi-individual and regional level were 1.11 (95 \% Cl=0.89-1.37), $1.14(95 \% \mathrm{Cl}=0.97-1.35)$ and $1.07(95 \% \mathrm{Cl}=0.94-1.23)$. In addition, significant meta-estimates of $\mathrm{PM}_{2.5}$ exposures were found in retrospective studies $(\mathrm{OR}=1.10,95 \% \mathrm{Cl}=1.01-1.21)$, prospective studies ( $\mathrm{OR}=1.42,95 \% \mathrm{Cl}=1.08-1.85)$, and studies conducted in the USA (OR $=1.16,95 \% \mathrm{Cl}=1.05-1.29)$.

Conclusions: Maternal $\mathrm{PM}_{2.5}$ exposure during pregnancy may increase the risk of preterm birth,but significant heterogeneity was found between studies. Exposure assessment methods, study designs and study settings might be important sources of heterogeneity, and should be taken into account in future meta-analyses.

Keywords: Fine particulate matter, Preterm birth, Meta-analysis, Adverse pregnancy outcome

\section{Background}

Preterm birth (before 37 weeks of gestation) is the leading cause of newborn deaths and the second-leading cause of death (after pneumonia) in children less than 5 years old [1]. More than 1 million children die each

\footnotetext{
* Correspondence: luoxiping07@aliyun.com; gztt_2002@163.com 'Gynecology Department, Guangdong Women and Children Hospital, No. 521, Xingnan Road, Panyu District, Guangzhou 511442, China

${ }^{5}$ Guangdong Provincial Institute of Public Health, Guangdong Provincial Center for Disease Control and Prevention, No. 160, Qunxian Road, Panyu District, Guangzhou 511430, China

Full list of author information is available at the end of the article
}

year worldwide due to complications of preterm birth. Many survivors face lifelong disabilities and chronic diseases, including learning disabilities, adult hypertension, diabetes, coronary heart disease, and visual and hearing problems $[1,2]$. An emerging body of evidence indicates that ambient air pollution may play an important role in the incidence of preterm birth [3, 4]. As a prominent component of the ambient air pollution mixture, fine particulate matter $\left(\mathrm{PM}_{2.5}\right.$, aerodynamic diameter $\left.<2.5 \mu \mathrm{m}\right)$ may cause greater harm to human health due to its specific characteristics such as smaller diameter, larger surface 
area, and longer suspension time in air [5, 6]. Although previous studies have estimated the association between $\mathrm{PM}_{2.5}$ exposure during pregnancy and preterm birth, the results have been inconsistent and remain controversial [7-10].

To quantitatively summarize the association between $\mathrm{PM}_{2.5}$ exposure and preterm birth risk, a few metaanalyses have been conducted during the past several years [11-13]. However, due to some methodological issues in previous studies, further research is needed. For example, all three meta-analyses found a significant heterogeneity between included studies [11-13]. According to the Cochrane guide, it is not appropriate to simply combine the results of articles with significant heterogeneity [14]. Although some authors have recognized this issue in their studies, the limited number of included studies prevented them from quantitatively testing the sources of heterogeneity $[11,12]$. In the past several years, more studies have been conducted to estimate the association between maternal $\mathrm{PM}_{2.5}$ exposure and preterm birth, which provides an opportunity to quantitatively explore the sources of heterogeneity between previous studies and meta-analyses.

In this study, we collected previously published studies that assessed the association between $\mathrm{PM}_{2.5}$ exposure during pregnancy and preterm birth, and employed a meta-analysis model to quantitatively evaluate the effects of $\mathrm{PM}_{2.5}$ exposure during different phases of pregnancy on preterm birth. We further explored the modification of exposure measurement methods, study settings and study designs on the meta-estimates of $\mathrm{PM}_{2.5}$.

\section{Methods}

The methods for the analysis and inclusion criteria were specified in advance and documented in a protocol.

\section{Literature search}

We searched for all publications indexed in the MEDLINE, PUBMED and EMBASE databases as well as the China Biological Medicine and Wanfang databases during November and December 2014. The search strategies used combinations of the following key words: "air pollution", "particulate matter", "fine particulate matter", "fine particles", "PM", " $\mathrm{PM}_{2.5}$ ", "PM 2.5", "premature birth", "preterm birth", "PTB", "preterm delivery", "PTD" and "prematurity". We also manually searched the references of every primary study for additional publications. Further publications were also identified from review articles. Only publications in English or Chinese were considered.

\section{Inclusion and exclusion criteria}

We initially screened the titles and abstracts of all studies. Studies were excluded if they were not related to fine particulate matter and preterm birth. The remaining studies were noted as potentially eligible studies and were further viewed by two independent authors. The studies were included in this meta-analysis if they met the following criteria: (a) studies included $\mathrm{PM}_{2.5}$ exposure during pregnancy and preterm birth that was defined as a live birth before gestational week 37; (b) studies presented sample sizes and odds ratios (OR) with $95 \%$ confidence intervals (CI) or information that could be used to infer these results; (c) if more than one study was identified for the same population, only the study that included the most recent population or the most information was selected. Studies that did not meet the above criteria were excluded. The process of study selection is presented in detail in Fig. 1.

\section{Data extraction}

The following information was extracted from each study: authors, year and source of publication, study period, study setting, study design, $\mathrm{PM}_{2.5}$ exposure assessment methods, data sources, sample size, $\mathrm{PM}_{2.5}$ exposure windows, exposure range, and ORs and $95 \%$ CIs. If a study provided associations between preterm birth and $\mathrm{PM}_{2.5}$ exposure during the entire pregnancy and trimester-specific periods, all estimates were extracted. Several studies assessed $\mathrm{PM}_{2.5}$ exposure based on monitoring network data and remote sensing data; we preferentially chose estimates based on monitoring network data because this assessment method was more common across all studies, which could potentially reduce the heterogeneity between studies in this meta-analysis. In addition, because there is considerable co-linearity between pollutants originating from the same sources and not all studies adjusted for air pollutants other than $\mathrm{PM}_{2.5}$, we extracted estimates only from single pollutant models fully adjusted for other covariates. Eligibility assessment and all data extraction were conducted by two authors using a standard form, and discrepancies were resolved by discussion between authors. The authors adhered to PRISMA guidelines for meta syntheses. Ethical approval was not required for this meta analysis. We employed the New Castle Ottawa scale to assess the quality of all included studies [15]. For the retrospective studies, the quality assessment was based on participant selection, comparability and exposure assessment; For the prospective studies, the quality assessment was based on participant selection, comparability and outcome.

\section{Meta-analysis and statistical analysis}

Prior to performing the meta-analysis, we converted all ORs to a common exposure unit of $10 \mu \mathrm{g} / \mathrm{m}^{3}$ increase in $\mathrm{PM}_{2.5}$ exposure, which allowed us to quantitatively pool estimates from different studies. Firstly, all ORs and their 95\%CIs were converted by logarithms (ln), which 


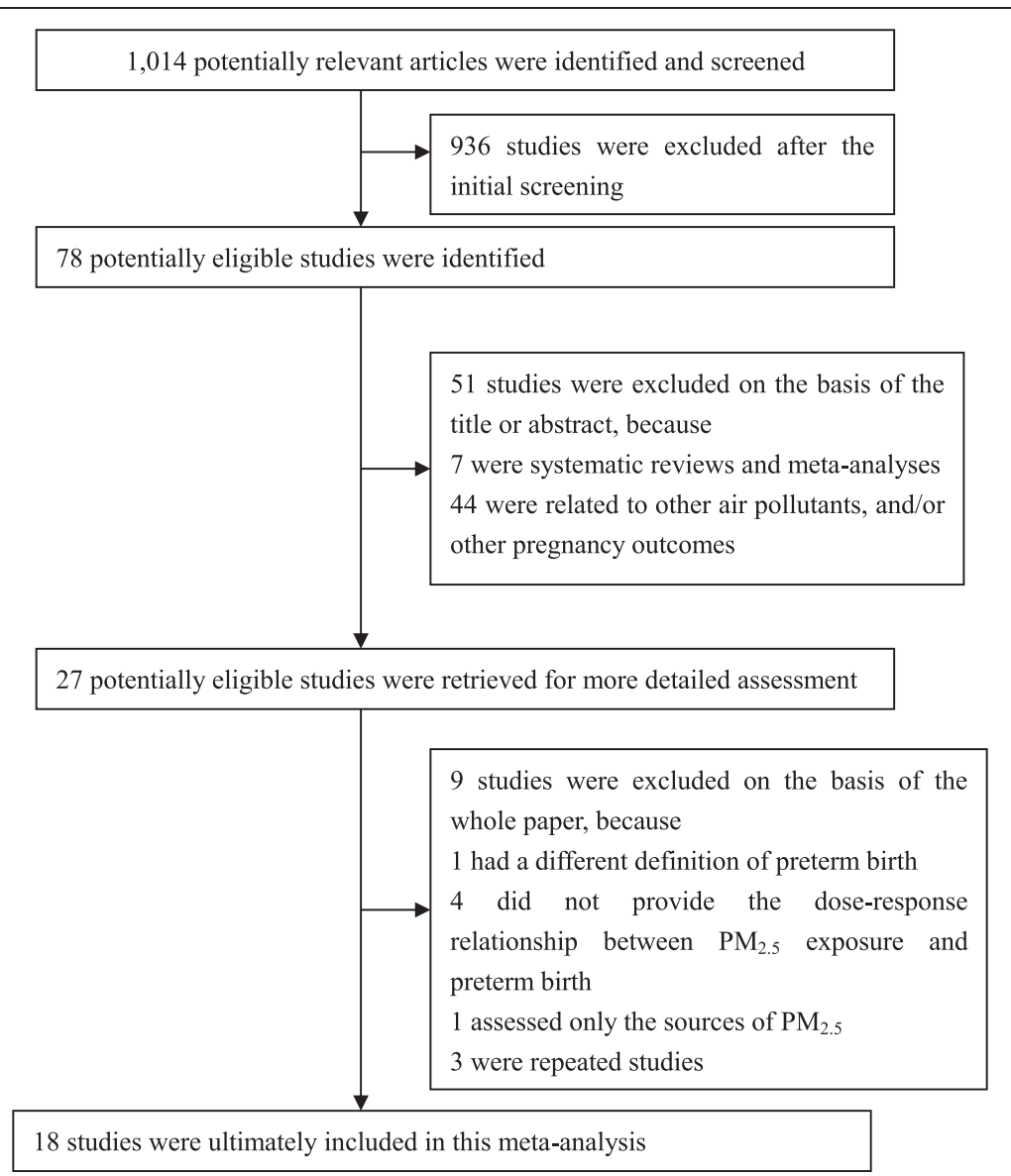

Fig. 1 Flow chart of the study selection process

were used to calculate the partial regression coefficients $(\beta)$ and their standard errors (se). Then the $\mathrm{OR}_{\mathrm{a}}(\mathrm{ad}-$ justed OR) for each $10 \mu \mathrm{g} / \mathrm{m}^{3}$ increase in $\mathrm{PM}_{2.5}$ exposure can be computed by the following formula:

$$
\mathrm{OR}_{\mathrm{a}}=\operatorname{EXP}(\beta \times 10 / \mathrm{x})
$$

Where $x\left(\mu \mathrm{g} / \mathrm{m}^{3}\right)$ is the exposure dose for OR reported in each included study. Similarly, the $95 \% \mathrm{CI}$ of $\mathrm{OR}_{\mathrm{a}}$ could also be calculated. We then conducted several meta-analyses of the identified studies to quantitatively estimate the associations of $\mathrm{PM}_{2.5}$ exposure during the entire pregnancy and trimester-specific exposure durations with preterm birth risks. Several secondary analyses were also conducted to estimate the pooled-effects of $\mathrm{PM}_{2.5}$ exposure during the entire pregnancy on preterm birth in subgroups with different exposure measurement methods, study designs, and study settings. These subgroup analyses aimed to explore the modification effects of these characteristics on the estimates of $\mathrm{PM}_{2.5}$ exposure on preterm birth and to further test their impacts on the heterogeneity in the reported associations.
Three exposure measurement methods were identified in the included studies: individual-level, semi-individuallevel, and regional-level exposure assessment. All these three assessment methods were based on residential level. Individual-level exposure was assessed using complicated dispersion models based on traffic, meteorology, roadway geometry, vehicle emission, air quality monitoring, and land use databases $[16,17]$. These models could estimate each subject's daily $\mathrm{PM}_{2.5}$ exposure level with high accuracy. Semi-individual exposure was estimated using the daily $\mathrm{PM}_{2.5}$ concentration from the monitoring station nearest to the individual's residence $[7,8]$. Regional-level exposure was calculated using the average $\mathrm{PM}_{2.5}$ concentration in a region or a grid with low resolution. This method did not consider the variation in $\mathrm{PM}_{2.5}$ concentration within a region, and assumed that all subjects in this region had the same $\mathrm{PM}_{2.5}$ exposure concentration. The $\mathrm{PM}_{2.5}$ data usually had been obtained from monitoring networks and remote sensing [18]. The study designs of all of the included studies were divided into two categories: retrospective and prospective. In addition, several meta regression analyses were further employed to assess the 
impacts of study characteristics on the associations between $\mathrm{PM}_{2.5}$ exposure and preterm birth risks.

To explore the possible heterogeneity of study results, we hypothesized that effect size may differ according to the methodological quality of the studies. The heterogeneity of the included studies was assessed using the Q statistic and $\mathrm{I}^{2}$ statistic. Cochran's Q statistic was calculated by summing the squared deviations of each study's estimate from the overall meta-analysis estimate weighted by each study's contribution. A p-value was obtained by comparing the $\mathrm{Q}$ statistic with a chi-square distribution with $\mathrm{k}-1^{\circ}$ of freedom, where $\mathrm{k}$ is the number of included studies [19]. If the $p$-value was $<0.05$, then a random-effects model would be selected, otherwise a fixed-effects model would be selected [20, 21]. The $\mathrm{I}^{2}$ statistic $\left[I^{2}=(Q-d f) / Q \times 100\right]$ describes the percentage of variation across studies that is due to heterogeneity rather than chance. $\mathrm{I}^{2}>50 \%$ demonstrated that there is a statistically significant heterogeneity [19]. We also used funnel plot asymmetry to detect potential publication bias. Egger's regression was applied to test the funnel plot symmetry, with the inverse of the standard error as the independent variable and the standardized estimate of size effect as the dependent variable [22].

Finally, a series of sensitivity analyses was performed to test the robustness of our results. Because some subgroup analyses included very few studies, we conducted sensitivity analyses only overall and in sub-groups analyses that included more than five studies. For each sensitivity analysis, we individually removed a single study with the largest OR, the smallest OR, the largest standard error, and the smallest standard error from the meta-analyses.

All statistical tests were two-sided, and $P<0.05$ was considered statistically significant. We used R software (version 2.15.2; R Development Core Team 2012, www.R-project.org) to analyze the data.

\section{Results}

Search results and study characteristics

Twenty-seven potentially eligible studies were identified and assessed for full text. A total of nine studies were excluded for the following reasons: having a different definition of preterm birth $(n=1)$ [23], not providing the dose-response relationship between $\mathrm{PM}_{2.5}$ exposure and preterm birth $(n=4)$ [24-27], only assessing the sources of $\mathrm{PM}_{2.5}(n=1)$ [28], and duplication of studies whose primary results had already been included in other studies $(n=3)$ [29-31]. Eighteen studies were ultimately included in this meta-analysis, containing a total of more than 3,000 000 subjects with more than 299,000 preterm births [7-10, 16-18, 32-42]. Most studies (12/18) were conducted in the USA [7, 16, 18, 32, 34-40, 42]. There were 12 retrospective and six prospective studies. There were two studies assessing maternal $\mathrm{PM}_{2.5}$ exposure at individual, ten at semi-individual, and two at regional levels. The other four studies used two methods to assess $\mathrm{PM}_{2.5}$ exposure. The average Newcastle-Ottawa quality score is 8 . Detailed information about the included studies is presented in Table 1.

\section{The pooled effects of $\mathrm{PM}_{2.5}$ exposure in different trimesters of pregnancy on preterm birth}

We estimated a significant increase of preterm birth risk associated with overall $\mathrm{PM}_{2.5}$ exposure (per $10 \mu \mathrm{g} / \mathrm{m}^{3}$ increment) during pregnancy across all 13 included studies $(\mathrm{OR}=1.13$, $95 \% \mathrm{CI}=1.03-1.24)$ (Table 2 and Fig. 2). The pooled OR values of $\mathrm{PM}_{2.5}$ exposure in the first, second and third trimester were 1.08 (95\% CI $=0.92-1.26), 1.09$ (95\% CI = 0.82-1.44) and 1.08 (95\% CI = 0.99-1.17), respectively. We did not find any significant effects of $\mathrm{PM}_{2.5}$ exposure in either the first month $(\mathrm{OR}=1.10,95 \% \mathrm{CI}=$ 0.92-1.30) or the last month of gestation (OR $=1.05,95 \%$ $\mathrm{CI}=0.97-1.13$ ) (Table 2 and Fig. 2).

Subgroup analyses on the effects of exposure assessment methods, study designs and study settings on the associations between $\mathrm{PM}_{2.5}$ exposure during the entire pregnancy and preterm birth

We found numerically similar pooled associations between preterm birth risk and $\mathrm{PM}_{2.5}$ exposure in studies using different exposure assessment methods. The pooled ORs in the studies that assessed $\mathrm{PM}_{2.5}$ exposure at individual, semi-individual and regional levels were 1.11 (95\% CI =0.89-1.37), 1.14 (95\% CI=0.97-1.35) and 1.07 (95\% CI =0.94-1.23), respectively (Table 2 and Fig. 2).

We observed significant pooled estimates of $\mathrm{PM}_{2.5}$ on preterm in studies that used a retrospective $(\mathrm{OR}=1.10$, $95 \% \mathrm{CI}=1.01-1.21)$ or prospective study design $(\mathrm{OR}=$ 1.42 , $95 \% \mathrm{CI}=1.08-1.85)$. Furthermore, the latter metaestimate of $\mathrm{PM}_{2.5}$ was larger than the former (Table 2 and Fig. 2).

The pooled estimate of the association between $\mathrm{PM}_{2.5}$ exposure and preterm birth was statistically significant for studies that were conducted in the USA $(\mathrm{OR}=1.16$, $95 \% \mathrm{CI}=1.05-1.29)$, but the pooled estimate was not significant for studies that were conducted in other countries $(\mathrm{OR}=0.98,95 \% \mathrm{CI}=0.95-1.01)$ (Table 2 and Fig. 2).

In addition, several meta regression analyses were employed to further evaluate the impacts of study characteristics on the associations between $\mathrm{PM}_{2.5}$ exposure and preterm birth risks (Additional file 1: Figure S1). We observed similar results with the subgroup analyses. For instance, the combined estimate of $\mathrm{PM}_{2.5}$ exposure during the entire pregnancy were higher in prospective studies than in retrospective studies $(\beta=0.25, P=0.120)$. 
Table 1 Characteristics of the studies included in the meta-analysis

\begin{tabular}{|c|c|c|c|c|c|c|c|c|c|c|}
\hline Authors & Study setting & $\begin{array}{l}\text { Study } \\
\text { period }\end{array}$ & Study design & $\begin{array}{l}\text { Exposure assessment } \\
\text { level }\end{array}$ & Data source & $\begin{array}{l}\text { No. of } \\
\text { participants }\end{array}$ & $\begin{array}{l}\text { No. of } \\
\text { cases }\end{array}$ & $\begin{array}{l}\text { Exposure } \\
\text { period }\end{array}$ & $\begin{array}{l}\text { Exposure range } \\
\left(\text { mean }(\mathrm{QQR}) \mu \mathrm{g} / \mathrm{m}^{3}\right)\end{array}$ & $\begin{array}{l}\text { Quality } \\
\text { score }^{\mathrm{a}}\end{array}$ \\
\hline Wilhelm et al. [39] & California, USA & $1999-2000$ & Retrospective & Semi-individual level & Monitoring network data & 106,483 & 92,68 & TS & $21.0(\mathrm{NA})$ & 8 \\
\hline Huynh et al. [7] & California, USA & 1999-2000 & Retrospective & Semi-individual level & Monitoring network data & 42,692 & 10,673 & WP and TS & $18.0(8.7)$ & 8 \\
\hline Jalaludin et al. [33] & Sydney, Australia & 1998-2000 & Retrospective & $\begin{array}{l}\text { Regional level and } \\
\text { semi-individual level }\end{array}$ & Monitoring network data & 123,840 & 6011 & TS & $9.0(4.5)$ & 8 \\
\hline Ritz et al. [37] & California, USA & 2003 & Prospective & Semi-individual level & Monitoring network data & 58,316 & 5924 & TS & $20.0(\mathrm{NA})$ & 7 \\
\hline Brauer et al. [8] & Vancouver, Canada & 1999-2002 & Prospective & Semi-individual level & Monitoring network data & 70,249 & 3748 & WP & $5.1(1.1)$ & 7 \\
\hline Wu et al. [16] & California, USA & 1997-2006 & Retrospective & Individual level & Monitoring network data & 81,186 & 6712 & WP & $1.8(1.4)$ & 9 \\
\hline Gehring et al. [17] & $\begin{array}{l}\text { North, west, and center } \\
\text { of the Netherlands }\end{array}$ & 1996-1997 & Prospective & Individual level & $\begin{array}{l}\text { Monitoring network data and } \\
\text { land use regression model }\end{array}$ & 3853 & 165 & WP and TS & $20.1(4.6)$ & 7 \\
\hline Rudra et al. [38] & Washington, USA & 1996-2006 & Retrospective & Semi-individual level & Monitoring network data & 3509 & 369 & TS & 10.1 (NA) & 9 \\
\hline Kloog et al. [34] & Massachusetts, USA & $2000-2008$ & Retrospective & Semi-individual level & Remote sensing data & 634,244 & 61,972 & WP & $9.6(5.3)$ & 9 \\
\hline Lee et al. [35] & Pittsburgh, USA & 1997-2002 & Prospective & Semi-individual level & Monitoring network data & 34,705 & 1940 & TS & $15.6(4.0)$ & 7 \\
\hline Chang et al. 2015 & Atlanta, USA & 1999-2005 & Retrospective & Semi-individual level & Monitoring network data & 175,891 & 18,648 & WP and TS & $17.3(3.1)$ & 8 \\
\hline Fleischer et al. [10] & 22 countries & 2004-2008 & Retrospective & Regional level & Remote sensing data & 192,900 & 13,379 & WP & 1.4-98.1 (NA) & 7 \\
\hline $\begin{array}{l}\text { Nannam et al. } 2014 \\
\text { [41] }\end{array}$ & Northwest England & $2004-2008$ & Retrospective & $\begin{array}{l}\text { Semi-individual level } \\
\text { and individual level }\end{array}$ & Monitoring network data & 265,613 & 38,608 & WP and TS & $22.1(4.6)$ & 9 \\
\hline Ha et al. [42] & Florida, USA & $2004-2005$ & Retrospective & $\begin{array}{l}\text { Regional level and } \\
\text { semi-individual level }\end{array}$ & Monitoring network data & 423,719 & 39,082 & WP and TS & $9.9(2.0)$ & 8 \\
\hline Hyder et al. [18] & $\begin{array}{l}\text { Connecticut and } \\
\text { Massachusetts, USA }\end{array}$ & 2000-2006 & Retrospective & $\begin{array}{l}\text { Regional level and } \\
\text { semi-individual level }\end{array}$ & $\begin{array}{l}\text { Monitoring network data and } \\
\text { remote sensing data }\end{array}$ & 647,942 & 41,868 & WP and TS & $11.9(2.4)$ & 8 \\
\hline Gray et al. [32] & North Carolina, USA & $2002-2006$ & Retrospective & Regional level & Monitoring network data & 457,642 & 40,746 & WP & $13.6(2.0)$ & 8 \\
\hline Pereira et al. [9] & Connecticut, USA & $2000-2006$ & Prospective & Semi-individual level & Monitoring network data & 61,688 & - & WP and TS & $12.4(2.3)$ & 9 \\
\hline Pereira et al. [56] & Perth, Australia & 1997-2007 & Prospective & Semi-individual level & Monitoring network data & 31,567 & - & WP and TS & $8.6(2.2)$ & 9 \\
\hline
\end{tabular}

NA: Data not available

-: The number of cases was not available because these studies were longitudinal studies that assessed the effects of $\mathrm{PM}_{2.5}$ on preterm birth across successive pregnancies. NA: Data not available 
Table 2 Pooled associations between $\mathrm{PM}_{2.5}$ exposure (per $10 \mu \mathrm{g} / \mathrm{m}^{3}$ increment) during pregnancy and preterm birth risks in different subgroups

\begin{tabular}{|c|c|c|c|c|c|c|c|c|c|}
\hline \multirow[t]{2}{*}{ Subgroups } & \multirow{2}{*}{$\begin{array}{l}\text { No. of } \\
\text { studies }\end{array}$} & \multicolumn{2}{|c|}{ Heterogeneity test } & \multirow{2}{*}{$\begin{array}{l}\text { Summary OR } \\
(95 \% \mathrm{Cl})\end{array}$} & \multicolumn{2}{|c|}{ Hypothesis test } & \multirow{2}{*}{$\begin{array}{l}I^{2} \\
(\%)\end{array}$} & \multicolumn{2}{|c|}{ Egger's test } \\
\hline & & $\bar{Q}$ & $P$ & & $\bar{z}$ & $P$ & & $\mathrm{t}$ & $P$ \\
\hline Exposure during the entire pregnancy & 13 & 80.51 & $<0.001$ & $1.13^{*}(1.03-1.24)$ & 2.59 & 0.010 & 91.4 & 2.20 & 0.051 \\
\hline \multicolumn{10}{|l|}{ Specific trimester } \\
\hline First trimester exposure & 10 & 89.14 & $<0.001$ & $1.08(0.92-1.26)$ & 0.96 & 0.334 & 91.3 & 0.68 & 0.517 \\
\hline Second trimester exposure & 5 & 138.69 & $<0.001$ & $1.09(0.82-1.44)$ & 0.60 & 0.548 & 98.7 & 0.311 & 0.776 \\
\hline Third trimester exposure & 9 & 44.83 & $<0.001$ & $1.08^{* *}(0.99-1.17)$ & 1.70 & 0.089 & 92.1 & 1.58 & 0.157 \\
\hline First month of gestation & 3 & 22.03 & $<0.001$ & $1.10(0.92-1.30)$ & 1.03 & 0.301 & 91.0 & 0.58 & 0.666 \\
\hline Within one month before birth & 6 & 51.49 & $<0.001$ & $1.01(0.86-1.19)$ & 0.09 & 0.926 & 96.8 & 0.03 & 0.980 \\
\hline \multicolumn{10}{|l|}{ Exposure assessment method ${ }^{a}$} \\
\hline Individual exposure & 3 & 4.94 & 0.085 & $1.11(0.89-1.37)$ & 0.93 & 0.352 & 61.3 & 1.74 & 0.332 \\
\hline Semi-individual exposure & 9 & 55.86 & $<0.001$ & $1.14(0.97-1.35)$ & 1.56 & 0.119 & 93.0 & 0.35 & 0.737 \\
\hline Regional level & 4 & 46.19 & $<0.001$ & $1.07(0.94-1.23)$ & 1.00 & 0.319 & 93.8 & 0.11 & 0.921 \\
\hline \multicolumn{10}{|l|}{ Study design ${ }^{a}$} \\
\hline Retrospective studies & 9 & 70.98 & $<0.001$ & $1.10^{*}(1.01-1.21)$ & 2.12 & 0.034 & 93.3 & 2.31 & 0.055 \\
\hline Prospective studies & 4 & 4.64 & 0.201 & $1.42^{*}(1.08-1.85)$ & 2.52 & 0.012 & 39.5 & 0.10 & 0.927 \\
\hline \multicolumn{10}{|l|}{ Study setting ${ }^{a}$} \\
\hline USA & 8 & 50.49 & $<0.001$ & $1.16^{*}(1.05-1.29)$ & 2.73 & 0.006 & 90.6 & 1.80 & 0.121 \\
\hline Others & 5 & 7.90 & 0.095 & $0.98(0.95-1.01)$ & 1.11 & 0.268 & 0.1 & 1.62 & 0.205 \\
\hline
\end{tabular}

${ }^{a}$ : All of these subgroup analyses were conducted for the studies that assessed the association between $\mathrm{PM}_{2.5}$ exposure during the entire pregnancy and preterm birth. All of these estimates were ORs for each $10 \mu \mathrm{g} / \mathrm{m}^{3}$ increment of $\mathrm{PM}_{2.5}$ exposure during the entire pregnancy

*: $p<0.05$

**: $0.05<p<0.10$

\section{Sensitivity analyses on the associations between $\mathrm{PM}_{2.5}$ exposure and preterm birth}

In the meta-analysis that included studies assessing $\mathrm{PM}_{2.5}$ exposure at the semi-individual level, the $\mathrm{PM}_{2.5}$ metaestimate became significant after excluding a single study with the smallest effect size. Beyond that, we did not find any significant change in the $\mathrm{PM}_{2.5}$ meta-estimates in other meta-analyses after excluding a single study with the largest effect size, the smallest effect size, the largest standard error, or the smallest standard error (Fig. 3).

\section{Heterogeneity and publication bias}

We observed significant heterogeneities in most of the meta-analyses. However, in some subgroup analyses, such as the subgroup of prospective studies, there were no significant heterogeneities between studies. These findings indicate that the three characteristics that we took into account in this study were important sources of heterogeneities between studies. We did not find any statistically significant publication bias in any of the meta-analyses (Table 2 and Fig. 4).

\section{Discussion}

In this meta-analysis, we quantitatively assessed the association between maternal $\mathrm{PM}_{2.5}$ exposure during pregnancy and preterm birth risk. We observed a clearly significant association between $\mathrm{PM}_{2.5}$ exposure during pregnancy and preterm birth risk, which is consistent with the results of previous meta-analyses $[11,13]$. Sapkota et al. estimated a pooled OR of $1.15(95 \% \mathrm{CI}=1.14-1.16)$ for preterm birth per $10 \mu \mathrm{g} / \mathrm{m}^{3}$ increment in $\mathrm{PM}_{2.5}$ exposure during the entire pregnancy [11]. Zhu et al. reported that a $10 \mu \mathrm{g} / \mathrm{m}^{3}$ increase in $\mathrm{PM}_{2.5}$ exposure over the entire pregnancy was positively associated with a $10 \%$ (95 CI \% $=3.0-18 \%$ ) increase in preterm birth risk [11] Stieb et al.'s meta-analysis also found a positive but nonsignificant association between $\mathrm{PM}_{2.5}$ exposure and preterm birth $(\mathrm{OR}=1.05,95 \mathrm{CI} \%=0.98-1.13)$. The lack of statistical significance may be due to the small quantity of included studies $(n=4)$ [12]. These results further demonstrate the adverse effect of $\mathrm{PM}_{2.5}$ exposure during pregnancy on preterm birth. Air pollution is ubiquitous, and all populations are exposed to it at some level. Immature fetuses are more susceptible to air pollution [43]. Therefore, these results are important for policy makers and public health practitioners worldwide.

Although the mechanisms of $\mathrm{PM}_{2.5}$ leading to preterm birth are not well understood, inhaled $\mathrm{PM}_{2.5}$ can penetrate the gas exchange region of the lungs and enter the bloodstream. Toxic chemicals such as carcinogenic polycyclic aromatic hydrocarbons and harmful metals could cause systemic oxidative stress, oxidative stress-induced DNA 


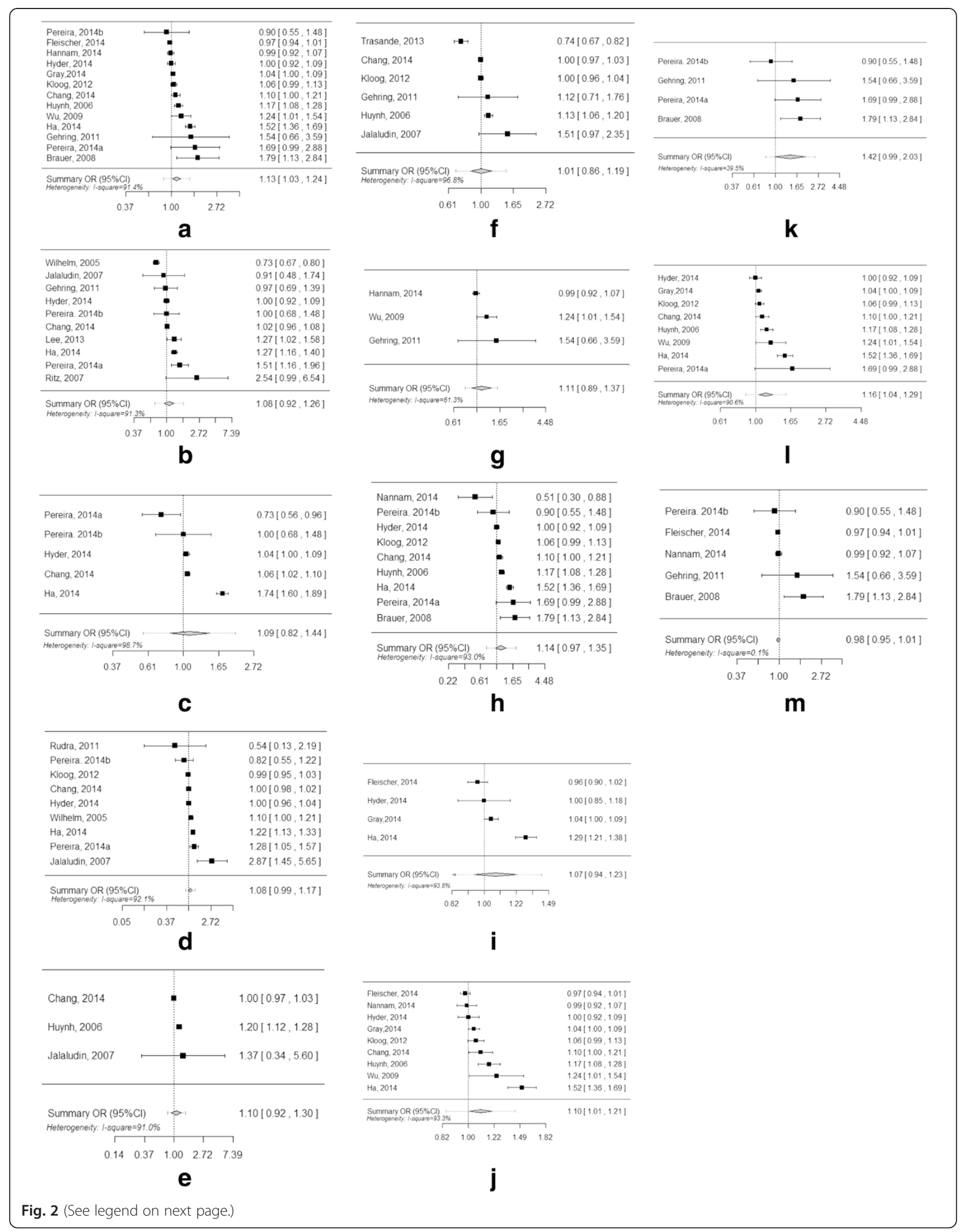


(See figure on previous page.)

Fig. 2 Forest plots for the pooled ORs for the association between $\mathrm{PM}_{2.5}$ exposure (per $10 \mathrm{\mu g} / \mathrm{m}^{3}$ increment) during the pregnancy and preterm birth. a: In studies that assessed $\mathrm{PM}_{2.5}$ exposure during the entire pregnancy. $\mathbf{b}$ : In studies that assessed $\mathrm{PM}_{2.5}$ exposure in the first trimester. $\mathbf{c}$ : In studies that assessed $\mathrm{PM}_{2.5}$ exposure in the second trimester. $\mathbf{d}$ : In studies that assessed $\mathrm{PM}_{2.5}$ exposure in the third trimester. e: In studies that assessed $\mathrm{PM}_{2.5}$ exposure in the first month of gestation. $\mathbf{f}$ : In studies that assessed $\mathrm{PM}_{2.5}$ exposure within one month before birth. $\mathbf{g}$ : In studies that assessed $\mathrm{PM}_{2.5}$ exposure at individual level. $\mathbf{h}$ : In studies that assessed $\mathrm{PM}_{2.5}$ exposure at semi-individual level. $\mathbf{i}$ : In studies that assessed PM 2.5 exposure at regional level. $\mathbf{j}$ : In retrospective studies. $\mathbf{k}$ : In prospective studies. I: In studies conducted in the USA. $\mathbf{m}$ : In studies conducted in other countries

damage, pulmonary and placental inflammation, blood coagulation, endothelial dis-function, and hemodynamic changes [44]. These responses could interfere with the transplacental oxygen and nutrient transport from mothers to fetuses, and has the potential to negatively impact fetal growth and development, particularly during critical periods of organogenesis [43, 45, 46]. In addition, The early activation of cytokines favoring inflammation may play an important role in the $\mathrm{PM}_{2.5}$-preterm link, because inflammatory mediators such as interleukin $1-\beta$ (IL-1 $\beta$ ) and tumor necrosis factor- $\alpha$ (TNF- $\alpha)$ can trigger the premature onset of labor [46].

The question of which gestational windows are more susceptible to air pollution has been explored in several previous studies. Although some studies supported early pregnancy (the first month or first trimester) [7, 35, 37], other studies supported later pregnancy (the third trimester, the last month, or the last week) $[33,39]$ as the window of susceptibility. A meta-analysis also observed a pronounced association between $\mathrm{PM}_{2.5}$ exposure during the third trimester and preterm risk [11]. It was debated that $\mathrm{PM}_{2.5}$ exposure during the later pregnancy might induce early activation of cytokines favoring inflammation, and trigger the premature onset of labor [46]. By contrast, the implantation of the fetus and the formation of the placenta occur during the first trimester, and higher $\mathrm{PM}_{2.5}$ exposure during this time period might cause genetic mutations, and hence increase the risks of fetal malformation, miscarriage and even death [47]. These serious harmful effects might attenuate the association between $\mathrm{PM}_{2.5}$ exposure in early pregnancy and preterm outcome. However, in this study we observed nearly identical pooled estimates of $\mathrm{PM}_{2.5}$ exposure during the first, second and third trimester, which indicates that more studies are needed in the future to explore which gestational windows are more susceptible to air pollution.

Exposure assessment is an important issue in studies estimating the effects of ambient air pollution on health. In this meta-analysis, we selected studies that assessed $\mathrm{PM}_{2.5}$ exposure at the individual, semi-individual or regional level. Using monitoring data for nearby areas or regional average $\mathrm{PM}_{2.5}$ concentrations measured at monitoring stations may provide a misrepresentation of exposure because this method does not take into account the spatial misalignment between an individual's residence and monitoring sites, and ignores the fact that individuals have different activity models (indoor and outdoor activity time) and could have changed their residential address during pregnancy [8, 48, 49]. Some recent studies used complicated dispersion models to quantitatively assess individual $\mathrm{PM}_{2.5}$ exposure [16, 17]. These models included data on several variables including traffic, meteorology, roadway geometry, vehicle emission, air quality, and land use. However, the accessibility of these datasets usually limits the wide employment of these dispersion models, particularly in some developing countries where the information on land use, traffic and vehicle emission is limited. In recent years, some studies used personal monitors to assess maternal exposure to air pollutants in different trimesters $[50,51]$. These methods could theoretically reduce the bias in exposure assessment. In this study, although we observed stronger pooled associations between $\mathrm{PM}_{2.5}$ exposure and preterm birth in studies that assessed $\mathrm{PM}_{2.5}$ exposure at the individual and semiindividual levels than for studies that used regional-level methods, the lack of significant associations indicate that more studies are needed in the future, especially studies assessing $\mathrm{PM}_{2.5}$ exposure at the individual level. For example, we only included three studies that used the individual-level assessment method, and their pooled estimate was dominated by a single study.

It is well known that the toxicity and health impacts of $\mathrm{PM}_{2.5}$ may vary by geographic area [52]. Therefore, it is reasonable to conduct subgroup meta-analyses to test the variation in $\mathrm{PM}_{2.5}$ estimates between regions. In this study, because most of the included studies were conducted in the USA, we divided all studies into two groups (USA and other countries). However, we found a significant meta-estimate of $\mathrm{PM}_{2.5}$ exposure only for the US studies. This discrepancy may be partially related to the small number $(n=5)$ of studies in the second group, which indicates that more studies in countries other than the USA are needed, especially in middle or low income countries with higher levels of air pollution. For example, only one study has been found that assessed the association between $\mathrm{PM}_{2.5}$ exposure and preterm birth in China and India. These two countries have the most severe $\mathrm{PM}_{2.5}$ pollution [53], and the largest number of preterm births worldwide [1]. Studies in these countries could provide important information for policy 


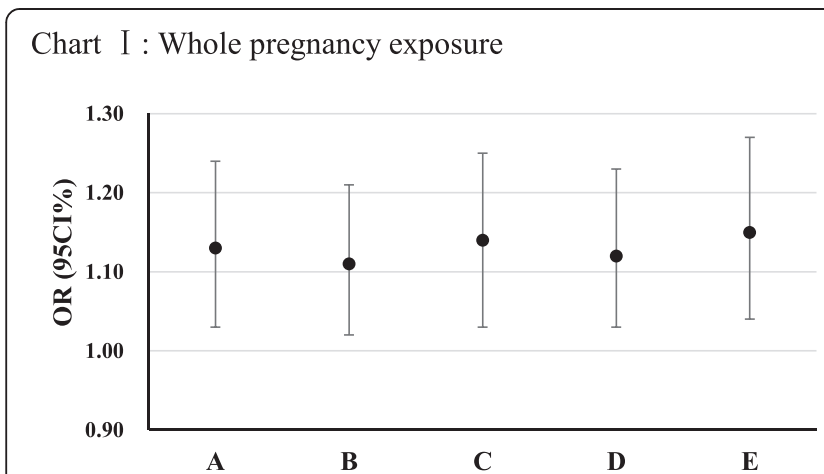

Chart III: Third trimester exposure

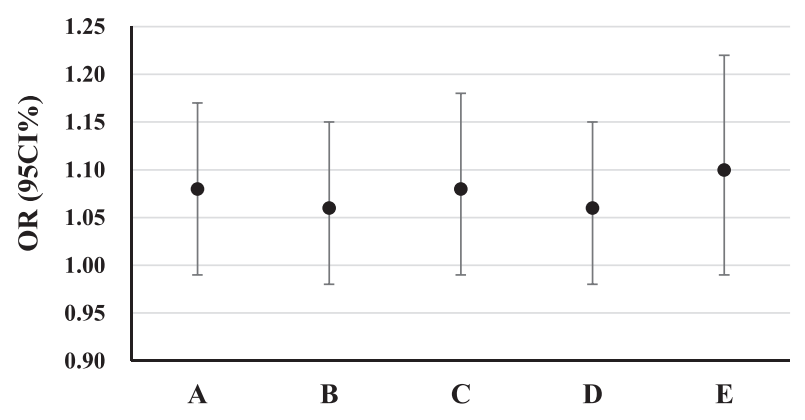

Chart V: Retrospective studies

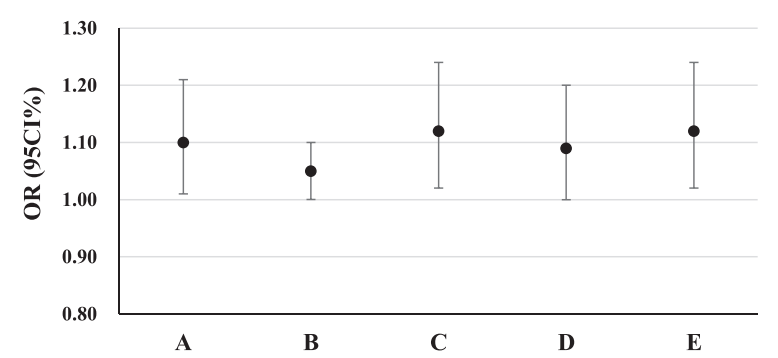

Chart II : First trimester exposure

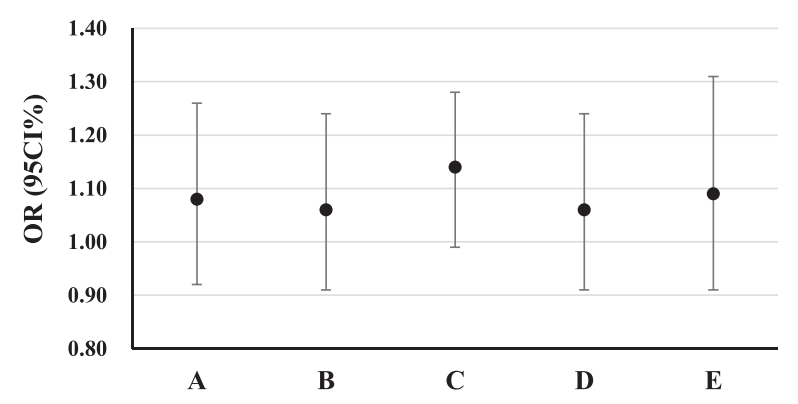

Chart IV: Semi-individual exposure

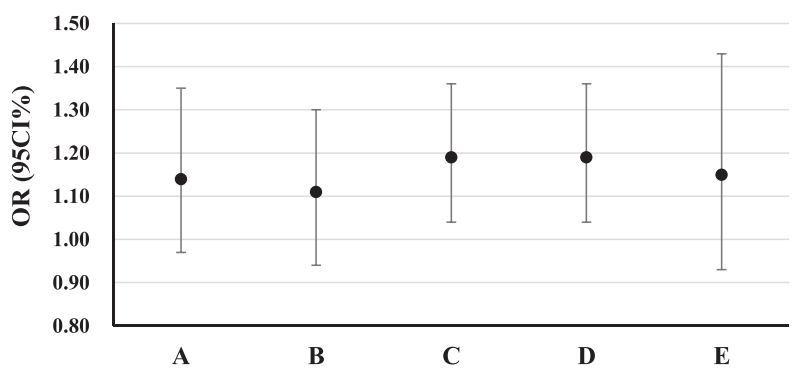

Chart VI: In the USA

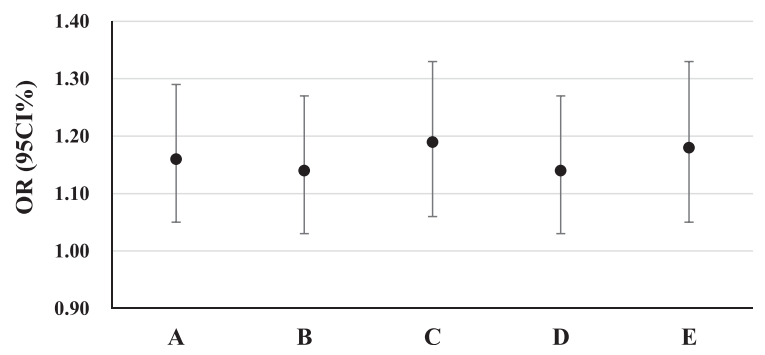

Fig. 3 Sensitivity analysis for the pooled effects of $\mathrm{PM}_{2.5}$ exposure (per $10 \mu \mathrm{g} / \mathrm{m}^{3}$ increment) on preterm birth risk in different subgroups. a: All studies were included; $b$ : The study with the largest effect size was excluded; $c$ : The study with the smallest effect size was excluded; $d$ : The study with the largest standard error was excluded; e: The study with the smallest standard error was excluded. Chart I: In studies that assessed the association between $\mathrm{PM}_{2.5}$ exposure during the entire pregnancy and preterm birth. Chart II: In studies that assessed the association between $\mathrm{PM}_{2.5}$ exposure in the first trimester and preterm birth. Chart III: In studies that assessed the association between PM 2.5 exposure in the third trimester and preterm birth. Chart IV: In studies that assessed the PM 2.5 exposure at the semi-individual level. Chart V: In retrospective studies. Chart VI: In studies that were conducted in the USA

makers and public health practitioners to reduce the health impacts of air pollution.

Although this meta-analysis estimated the pooled effects of $\mathrm{PM}_{2.5}$ concentrations on preterm birth risks, the limited number of studies restricted us from further exploring the effects of the chemical components of $\mathrm{PM}_{2.5}$ on preterm birth. $\mathrm{PM}_{2.5}$ is a mixture of multiple inorganic and organic components, and its health effects can vary based on components and origins $[54,55]$. Only two of the included studies assessed the association between the components and sources of $\mathrm{PM}_{2.5}$ and preterm birth. Pereira et al. observed that preterm birth in Connecticut, USA was associated with increased exposure to dust, motor vehicle emissions, oil combustion and regional sulfur $\mathrm{PM}_{2.5}$ sources during the entire pregnancy [56]. Darrow et al.'s study in Atlanta, USA found that preterm birth was significantly associated with sulfates and water-soluble metals in $\mathrm{PM}_{2.5}$, but not associated with other components [30]. These results demonstrate that studies on the association between $\mathrm{PM}_{2.5}$ components and sources and preterm birth are still limited, and more studies are needed in the future. 


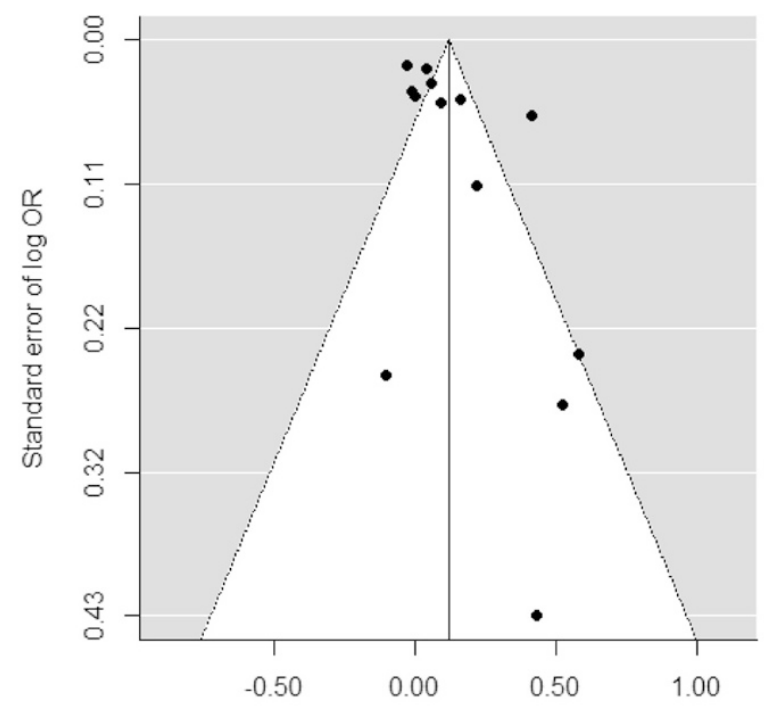

Log odds ratio

a

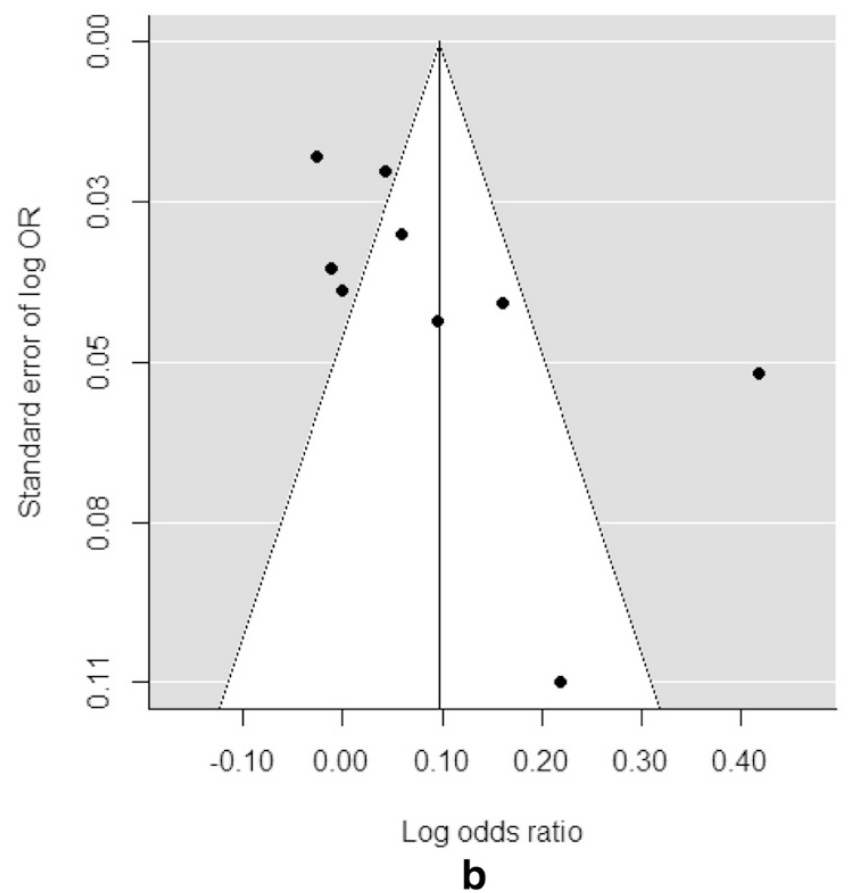

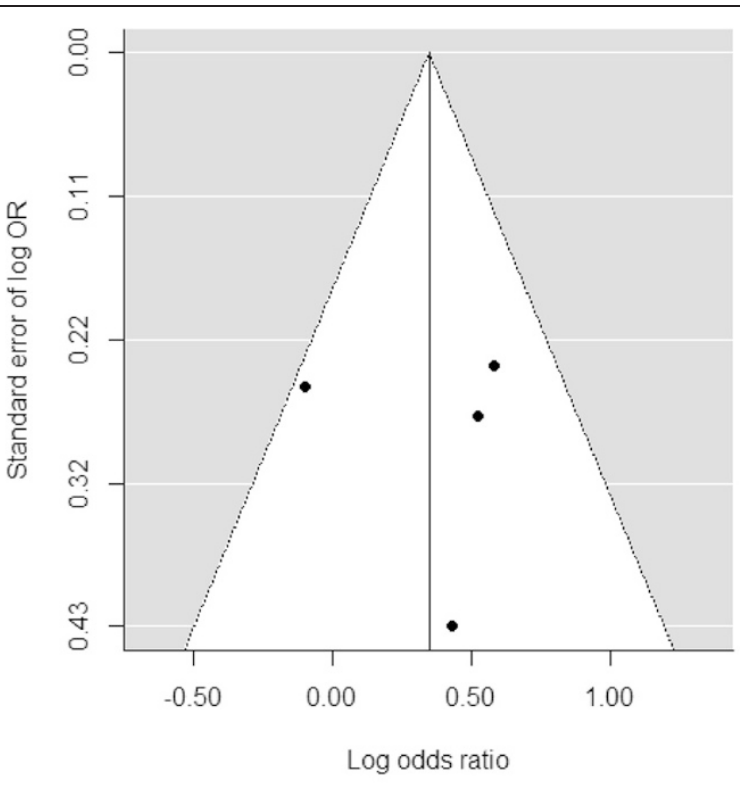

C

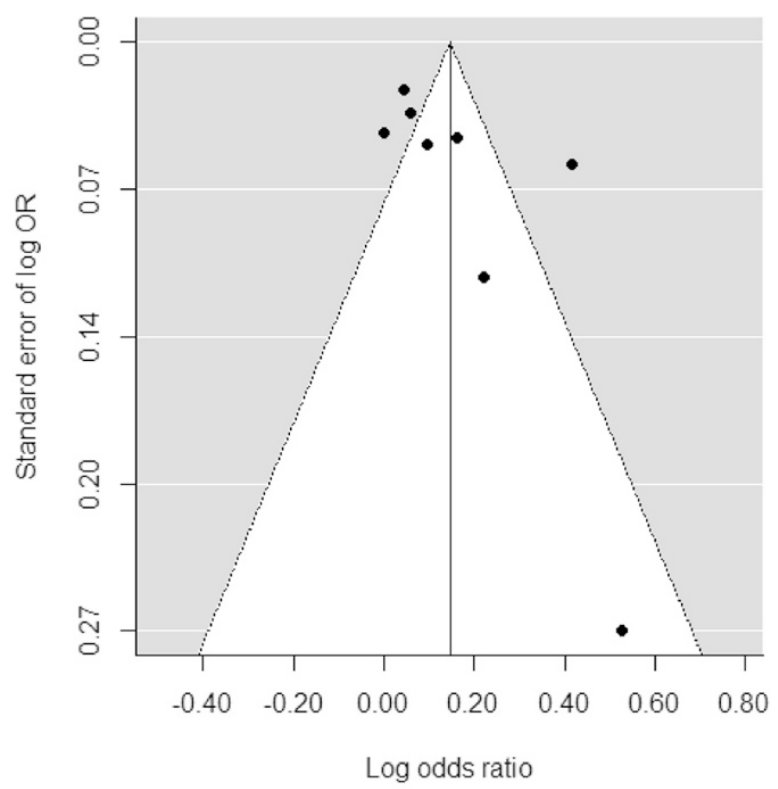

d

Fig. 4 Funnel plots for the meta-analyses assessing the associations between $\mathrm{PM}_{2.5}$ exposure (per $10 \mu \mathrm{g} / \mathrm{m}^{3}$ increment) during pregnancy and preterm birth. a: In studies that assessed $\mathrm{PM}_{2.5}$ exposure during the entire pregnancy. $\mathbf{b}$ : In retrospective studies. $\mathbf{c}$ : In prospective studies. $\mathbf{d}$ : In studies conducted in the USA

Another factor affecting the heterogeneity between studies is the way that the studies controlled for confounders [57]. All of the studies included in this metaanalysis provided adjusted estimates of $\mathrm{PM}_{2.5}$ exposure. Some common confounders, such as maternal age, race/ ethnicity, income, education, smoking status during pregnancy, infant sex, parity, and birth season, were adjusted for in most studies. However, almost all of the maternal and infant information was from public records, such as birth certificates, which limited the ability to control for other important confounders, such as maternal stress, activity level, nutrition, indoor pollution, and factors that varied spatially $[36,50,51]$. Therefore, improving the data quality of public records is one way to improve related 
studies. Future longitudinal studies that collect more detailed information at the individual level would be beneficial.

With reference to the limitations of this metaanalysis, we found high heterogeneity between included studies. Therefore, we used a random-effects model to quantitatively combine the individual estimate in studies with high heterogeneities. We also employed subgroup analyses and meta-regression analyses to explore the sources of heterogeneity. The results showed that although exposure assessment methods, study designs and study settings partially explained the heterogeneity, significant heterogeneities were still found in most subgroup analyses. These findings indicate that the heterogeneity across the included studies may also have been affected by other factors that we did not consider in this study, such as socioeconomic status and chemical constituents of $\mathrm{PM}_{2.5}$, due to the limited quantity of related studies. Therefore, further studies are needed to explore the sources of heterogeneity in the future.

\section{Conclusions}

In summary, this meta-analysis observed a clear association between $\mathrm{PM}_{2.5}$ exposure during pregnancy and preterm birth risk. However, a significant heterogeneity was found between included studies. The exposure assessment method, study design and study setting might be important sources of the heterogeneity, and should be taken into account in future meta-analyses. This study extends our understanding of the effects of maternal $\mathrm{PM}_{2.5}$ exposure on preterm birth, and highlights that it is crucial to reduce ambient $\mathrm{PM}_{2.5}$ pollution and reduce maternal $\mathrm{PM}_{2.5}$ exposure during pregnancy to improve birth outcomes.

\section{Additional file}

Additional file 1: Figure S1. Meta regression analyses on the effects of study characteristics on the associations between $\mathrm{PM}_{2.5}$ exposure and preterm birth risks. Chart A: The effects of $\mathrm{PM}_{2.5}$ exposure during different trimester (the first, second and third trimester) of pregnancy on the pooled estimate of $\mathrm{PM}_{2.5}$. Chart B: The effects of $\mathrm{PM}_{2.5}$ exposure assessed by different methods (regional, semi-individual and individual level) on the pooled estimate of $\mathrm{PM}_{2.5}$. Chart $\mathrm{C}$ : The effects of study designs (retrospective and prospective studies) on the pooled estimate of $\mathrm{PM}_{2.5}$. Chart D: The effects of study settings (the USA and other countries) on the pooled estimate of $\mathrm{PM}_{2.5}$ (DOCX $56 \mathrm{~kb}$ )

\section{Abbreviations}

$\mathrm{PM}_{2.5}$ : Fine particulate matter with aerodynamic diameter $<2.5 \mu \mathrm{m}$; OR: Odds ratio; Cl: Confidence interval; USA: The United States of America;

PTB: Preterm birth; PTD: Preterm delivery; NA: Data not available.

\section{Competing interests}

The authors declare that they have no competing interests.

\section{Authors' contributions}

XS participated in the design and coordination of the study, and drafting the manuscript. XL conceived the study. CZ searched for the studies, collected and analyzed the data. RC participated in the design of this study and edited the manuscript. CD participated in the design of this study and edited the manuscript. BZ did the data management and analyzed the data. TL conceived the study. All authors read and approved the final manuscript.

\section{Acknowledgments and funding}

This work was supported by the, Natural Science Foundation of Guangdong Province (2015A030310220) National Natural Science Foundation of China (81502819) , Fundamental Research Funds for the Central Universities

(12ykpy13) and Postdoctoral Science Foundation of China (2013 M542230)

\section{Author details}

'Gynecology Department, Guangdong Women and Children Hospital, No. 521, Xingnan Road, Panyu District, Guangzhou 511442, China. ${ }^{2}$ Sydney South West Clinical School, Faculty of Medicine, University of New South Wales, Sydney, Australia. ${ }^{3}$ Faculty of Science, University of Technology Sydney, Ultimo, Australia. ${ }^{4}$ Department of Preventive Medicine, School of Public Health, Sun Yat-sen University, Guangzhou 510080, China. ${ }^{5}$ Guangdong Provincial Institute of Public Health, Guangdong Provincial Center for Disease Control and Prevention, No. 160, Qunxian Road, Panyu District, Guangzhou 511430, China. 'Environment and Health, Guangdong Provincial Key Medical Discipline of Twelfth Five-Year Plan, Guangzhou 511430, China.

Received: 15 March 2015 Accepted: 10 November 2015

Published online: 18 November 2015

\section{References}

1. March of Dimes, PMNCH, Save the Children, WHO. Born Too Soon: The Global Action Report on Preterm Birth. CP Howson, MV Kinney, JE Lawn, editors. Geneva; World Health Organization. 2012.

2. Saigal S, Doyle LW. An overview of mortality and sequelae of preterm birth from infancy to adulthood. Lancet. 2008;371(9608):261-9.

3. Shah PS, Balkhair T, Knowledge Synthesis Group on Determinants of Preterm LBWb. Air pollution and birth outcomes: a systematic review. Environ Int. 2011;37(2):498-516.

4. Nieuwenhuijsen MJ, Dadvand P, Grellier J, Martinez D, Vrijheid M. Environmental risk factors of pregnancy outcomes: a summary of recent meta-analyses of epidemiological studies. Environ Health. 2013;12:6.

5. Englert N. Fine particles and human health - a review of epidemiological studies. Toxicol Lett. 2004;149(1):235-42.

6. Parker JD, Woodruff TJ, Basu R, Schoendorf KC. Air pollution and birth weight among term infants in California. Pediatrics. 2005;115(1):121-8.

7. Huynh M, Woodruff TJ, Parker JD, Schoendorf KC. Relationships between air pollution and preterm birth in California. Paediatr Perinat Ep. 2006;20(6):454-61.

8. Brauer M, Lencar C, Tamburic L, Koehoorn M, Demers P, Karr C. A cohort study of traffic-related air pollution impacts on birth outcomes. Environ Health Perspect. 2008;116(5):680-6.

9. Pereira G, Bell ML, Belanger K, de Klerk N. Fine particulate matter and risk of preterm birth and pre-labor rupture of membranes in Perth, Western Australia 1997-2007: A longitudinal study. Environ Int. 2014;73C:143-9.

10. Fleischer NL, Merialdi M, van Donkelaar A, Vadillo-Ortega F, Martin RV, Betran AP, et al. Outdoor air pollution, preterm birth, and low birth weight: analysis of the world health organization global survey on maternal and perinatal health. Environ Health Perspect. 2014;122(4):425-30.

11. Sapkota A, Chelikowsky AP, Nachman KE, Cohen AJ, Ritz B. Exposure to particulate matter and adverse birth outcomes: a comprehensive review and meta-analysis. Air Qual, Atmos HIth. 2012;5(4):369-81.

12. Stieb DM, Chen L, Eshoul M, Judek S. Ambient air pollution, birth weight and preterm birth: a systematic review and meta-analysis. Environ Res. 2012;117:100-11

13. Zhu X, Liu Y, Chen $Y$, Yao C, Che Z, Cao J. Maternal exposure to fine particulate matter (PM) and pregnancy outcomes: a meta-analysis. Environ Sci Pollut Res Int. 2015; DOI 10.1007/s11356-014-3458-7.

14. Higgins JP, Green S. Cochrane handbook for systematic reviews of interventions, vol. 5. Chichester: John Wiley \& Sons, Ltd; 2008.

15. Wells G, Shea B, O'connell D, Peterson J, Welch V, Losos M, et al. The Newcastle-Ottawa Scale (NOS) for assessing the quality of nonrandomised studies in meta-analyses. http://www.medicine.mcgill.ca/rtamblyn/Readings/ The\%20Newcastle\%20-\%20Scale\%20for\%20assessing\%20the\%20 quality $\% 20$ of\%20nonrandomised\%20studies\%20in\%20meta-analyses.pdf. [Accessed January 3, 2015] 
16. Wu J, Ren C, Delfino RJ, Chung J, Wilhelm M, Ritz B. Association between local traffic-generated air pollution and preeclampsia and preterm delivery in the south coast air basin of California. Environ Health Perspect. 2009;117(11):1773-9.

17. Gehring $U$, Wijga AH, Fischer $P$, de Jongste JC, Kerkhof M, Koppelman GH, et al. Traffic-related air pollution, preterm birth and term birth weight in the PIAMA birth cohort study. Environ Res. 2011;111(1):125-35.

18. Hyder A, Lee HJ, Ebisu K, Koutrakis P, Belanger K, Bell ML. PM2.5 exposure and birth outcomes: use of satellite- and monitor-based data. Epidemiology. 2014;25(1):58-67.

19. Higgins JP, Thompson SG, Deeks JJ, Altman DG. Measuring inconsistency in meta-analyses. BMJ. 2003;327(7414):557-60.

20. Hamra GB, Guha N, Cohen A, Laden F, Raaschou-Nielsen O, Samet JM, et al. Outdoor Particulate Matter Exposure and Lung Cancer: A Systematic Review and Meta-Analysis. Environ Health Perspect. 2014;122(9):906-11.

21. DerSimonian R, Laird N. Meta-analysis in clinical trials. Control Clin Trials. 1986;7(3):177-88

22. Egger M, Davey Smith G, Schneider M, Minder C. Bias in meta-analysis detected by a simple, graphical test. BMJ. 1997;315(7109):629-34.

23. Rappazzo KM, Daniels JL, Messer LC, Poole C, Lobdell DT. Exposure to fine particulate matter during pregnancy and risk of preterm birth among women in New Jersey, Ohio, and Pennsylvania, 2000-2005. Environ Health Perspect. 2014;122(9):992.

24. Chang HH, Reich BJ, Miranda ML. A spatial time-to-event approach for estimating associations between air pollution and preterm birth. J R Stat Soc: Ser C: Appl Stat. 2013;62(2):167-79.

25. Chang HH, Reich BJ, Miranda ML. Time-to-event analysis of fine particle air pollution and preterm birth: results from North Carolina, 2001-2005. Am J Epidemiol. 2012;175(2):91-8.

26. Warren J, Fuentes M, Herring A, Langlois P. Spatial-Temporal Modeling of the Association between Air Pollution Exposure and Preterm Birth: Identifying Critical Windows of Exposure. Biometrics. 2012;68(4):1157-67.

27. Symanski E, Davila M, McHugh MK, Waller DK, Zhang X, Lai D. Maternal Exposure to Fine Particulate Pollution During Narrow Gestational Periods and Newborn Health in Harris County, Texas. Matern Child Health J. 2014;18(8):2003-12.

28. Sram RJ, Benes I, Binkova B, Dejmek J, Horstman D, Kotesovec F, et al. Teplice program-the impact of air pollution on human health. Environ Health Perspect. 1996;104 Suppl 4:699-714.

29. Wu J, Wilhelm M, Chung J, Ritz B. Comparing exposure assessment methods for traffic-related air pollution in an adverse pregnancy outcome study. Environ Res. 2011;111(5):685-92.

30. Darrow LA, Klein M, Flanders WD, Waller LA, Correa A, Marcus M, et al. Ambient air pollution and preterm birth: a time-series analysis. Epidemiology. 2009;20(5):689-98.

31. Wilhelm M, Ghosh JK, Su J, Cockburn M, Jerrett M, Ritz B. Traffic-related air toxics and preterm birth: a population-based case-control study in Los Angeles County, California. Environ Health. 2011;10:89.

32. Gray SC, Edwards SE, Schultz BD, Miranda ML. Assessing the impact of race, social factors and air pollution on birth outcomes: a population-based study. Environ Health. 2014;13(4):1-8.

33. Jalaludin B, Mannes T, Morgan G, Lincoln D, Sheppeard V, Corbett S. Impact of ambient air pollution on gestational age is modified by season in Sydney, Australia. Environ Health. 2007;6(16):1-9.

34. Kloog I, Melly SJ, Ridgway WL, Coull BA, Schwartz J. Using new satellite based exposure methods to study the association between pregnancy PM2. 5 exposure, premature birth and birth weight in Massachusetts. Environ Health. 2012;11(1):1-8.

35. Lee PC, Roberts JM, Catov JM, Talbott EO, Ritz B. First trimester exposure to ambient air pollution, pregnancy complications and adverse birth outcomes in Allegheny County, PA. Matern Child Health J. 2013;17(3):545-55.

36. Pereira G, Belanger K, Ebisu K, Bell ML. Fine particulate matter and risk of preterm birth in connecticut in 2000-2006: a longitudinal study. Am J Epidemiol. 2014;179(1):67-74

37. Ritz B, Wilhelm M, Hoggatt KJ, Ghosh JKC. Ambient air pollution and preterm birth in the environment and pregnancy outcomes study at the University of California, Los Angeles. Am J Epidemiol. 2007;166(9):1045-52.

38. Rudra CB, Williams MA, Sheppard L, Koenig JQ, Schiff MA. Ambient carbon monoxide and fine particulate matter in relation to preeclampsia and preterm delivery in western Washington State. Environ Health Perspect. 2011;119(6):886-92

39. Wilhelm M, Ritz B. Local variations in $\mathrm{CO}$ and particulate air pollution and adverse birth outcomes in Los Angeles County, California, USA. Environ Health Perspect. 2005;113(9):1212-21.
40. Chang HH, Warren JL, Darrow LA, Reich BJ, Waller LA. Assessment of critical exposure and outcome windows in time-to-event analysis with application to air pollution and preterm birth study. Biostatistics. 2015;16(3):509-21. kxu060.

41. Hannam K, McNamee R, Baker P, Sibley C, Agius R. Air pollution exposure and adverse pregnancy outcomes in a large UK birth cohort: use of a novel spatio-temporal modelling technique. Scand J Work Environ Health. 2014; 40(5):518-30.

42. Ha S, Hu H, Roussos-Ross D, Haidong K, Roth J, Xu X. The effects of air pollution on adverse birth outcomes. Environ Res. 2014;134:198-204.

43. Backes $\mathrm{CH}$, Nelin T, Gorr MW, Wold LE. Early life exposure to air pollution: how bad is it? Toxicol Lett. 2013;216(1):47-53.

44. Parker JD, Woodruff TJ. Influences of study design and location on the relationship between particulate matter air pollution and birthweight. Paediatr Perinat Ep. 2008;22(3):214-27.

45. Kannan S, Misra DP, Dvonch JT, Krishnakumar A. Exposures to airborne particulate matter and adverse perinatal outcomes: a biologically plausible mechanistic framework for exploring potential effect modification by nutrition. Environ Health Perspect. 2006;114(11):1636-42.

46. Vadillo-Ortega F, Osornio-Vargas A, Buxton MA, Sánchez BN, Rojas-Bracho L, Viveros-Alcaráz $M$, et al. Air pollution, inflammation and preterm birth: A potential mechanistic link. Med Hypotheses. 2014;82(2):219-24.

47. Lin C-C, Santolaya-Forgas J. Current concepts of fetal growth restriction: part I. Causes, classification, and pathophysiology. Obstet Gynecol. 1998; 92(6):1044-55

48. Zeger SL, Thomas D, Dominici F, Samet JM, Schwartz J, Dockery D, et al. Exposure measurement error in time-series studies of air pollution: concepts and consequences. Environ Health Perspect. 2000;108(5):419-26.

49. Berrocal VJ, Gelfand AE, Holland DM, Burke J, Miranda ML. On the use of a PM2. 5 exposure simulator to explain birthweight. Environmetrics. 2011;22(4):553-71.

50. Jedrychowski W, Perera F, Mrozek-Budzyn D, Mroz E, Flak E, Spengler JD, et al. Gender differences in fetal growth of newborns exposed prenatally to airborne fine particulate matter. Environ Res. 2009;109(4):447-56.

51. Jedrychowski W, Bendkowska I, Flak E, Penar A, Jacek R, Kaim I, et al. Estimated risk for altered fetal growth resulting from exposure to fine particles during pregnancy: an epidemiologic prospective cohort study in Poland. Environ Health Perspect. 2004;112(14):1398-402.

52. Laden F, Neas LM, Dockery DW, Schwartz J. Association of fine particulate matter from different sources with daily mortality in six US cities. Environ Health Perspect. 2000;108(10):941-7.

53. Van Donkelaar A, Martin RV, Brauer M, Kahn R, Levy R, Verduzco C, et al. Global estimates of ambient fine particulate matter concentrations from satellite-based aerosol optical depth: development and application. Environ Health Perspect. 2010;118(6):847-55

54. Habre R, Moshier E, Castro W, Nath A, Grunin A, Rohr A, et al. The effects of PM2.5 and its components from indoor and outdoor sources on cough and wheeze symptoms in asthmatic children. J Expo Sci Env Epid. 2014:24:380-7.

55. Kelly FJ, Fussell JC. Size, source and chemical composition as determinants of toxicity attributable to ambient particulate matter. Atmos Environ. 2012; 60:504-26.

56. Pereira G, Bell ML, Lee HJ, Koutrakis $P$, Belanger K. Sources of Fine Particulate Matter and Risk of Preterm Birth in Connecticut, 2000-2006: A Longitudinal Study. Environ Health Perspect. 2014;122(10):1117-22.

57. Morello-Frosch R, Jesdale BM, Sadd JL, Pastor M. Ambient air pollution exposure and full-term birth weight in California. Environ Health. 2010;9(44):1-13. 